\title{
Dynamic Behaviour of the Confederation Bridge Under Seismic Loads
}

\author{
Lan Lin, Nove Naumoski and Murat Saatcioglu
}

Additional information is available at the end of the chapter

http://dx.doi.org/10.5772/50070

\section{Introduction}

The Confederation Bridge, which was opened for traffic in June 1997, is 12,910 m long and is one of the longest reinforced concrete bridges built over water in the world. The bridge crosses the Northumberland Strait in eastern Canada and connects the province of Prince Edward Island and the province of New Brunswick.

The bridge is located in a region known for very harsh environmental conditions. The Strait is covered by ice approximately three to four months in a year. Heavy storms with winds in excess of $100 \mathrm{~km} / \mathrm{h}$ are often experienced at the bridge site. Given the importance of the Confederation Bridge, its length, and the environmental conditions, special criteria were imposed in the design and construction of the bridge in order to provide a high degree of safety during its operational life. The bridge was designed for a service life of 100 years, which is twice the service life considered in the Canadian codes for highway bridges that were in use during the design of the Confederation Bridge, i.e., the CSA Standard CAN/CSA-S6-88 [1], and the Ontario Highway Bridge Design Code (OHBDC) [2]. A safety index of 4.0 was used in the design, compared with 3.5 specified in CAN/CSA-S6-88 and OHBDC. Load combinations and load resistance factors were developed specifically for the design of the bridge, as described in [3]. A number of assumptions had to be made in the design, particularly for the long-term properties of the materials in the specific environmental conditions and for the effects of various dynamic loads on the performance of the bridge. Given these assumptions, a comprehensive research program was undertaken to monitor and study the behaviour of the bridge. As part of this program, a study was conducted to investigate the dynamic performance of the bridge under seismic loads. The objective of the study was to compare the responses of the bridge for seismic actions representative of the seismic hazard at the bridge location with those used in the design. There are two major reasons for undertaking this study. First, significant advancements in 
the understanding of the eastern Canadian seismicity and in the methods for seismic hazard computations have been made since the design of the bridge in the mid 1990s, and therefore, a more accurate estimate of the seismic hazard at the bridge location can now be made. Second, recorded vibrations of the bridge are available which enable the development of an accurate analysis model of the as-built bridge.

This paper describes the main findings from the study. It includes: (i) a brief description of the bridge; (ii) an overview of the seismic parameters used in the design of the bridge; (iii) development of a finite element model of the bridge for use in the seismic analysis; (iv) selection of seismic ground motions representative of the seismic hazard at the bridge location; and (v) dynamic analysis of the bridge model and comparison of the analytical results with the design values.

\section{Description of the bridge}

The Confederation Bridge consists of two approach bridges at its ends and a main bridge between them (Fig. 1). The approach bridge at the Prince Edward Island end (i.e., the east end) is $555 \mathrm{~m}$ long and has 7 piers, and that at the New Brunswick end (i.e., the west end) is $1,275 \mathrm{~m}$ long and has 14 piers. The longest span of the approach bridges is $93 \mathrm{~m}$. The main bridge is 11,080 m long and has 44 piers, designated P1 to P44 in Fig. 1. Of the 45 spans of the main bridge, 43 spans are $250 \mathrm{~m}$ long and the two end spans are $165 \mathrm{~m}$ long. The cross section of the bridge girder is a single-cell trapezoidal box. The depth of the girder of the main bridge varies from $4.5 \mathrm{~m}$ at mid spans to $14 \mathrm{~m}$ at piers. The width of the bridge deck is $11 \mathrm{~m}$.

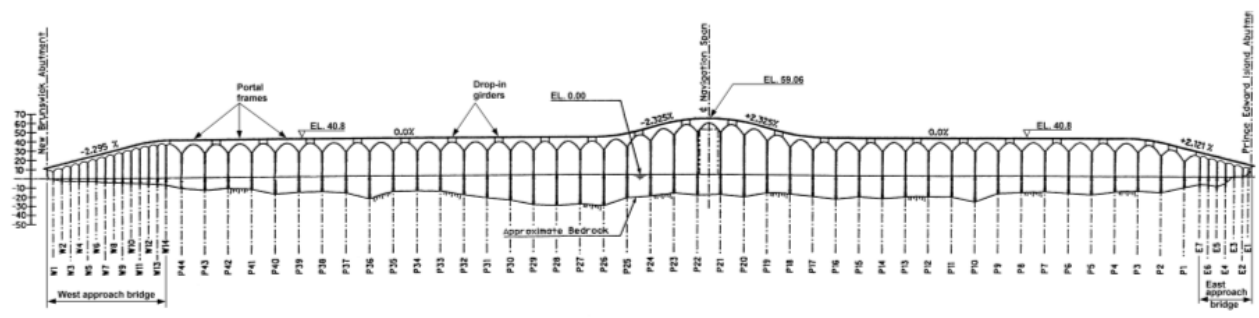

Figure 1. Elevation of the Confederation Bridge.

As shown in Fig. 1, the bridge deck of most of the main bridge is at elevation of $40.8 \mathrm{~m}$ above mean sea level (MSL). The height of the columns of this part of the bridge ranges from 38 to $62 \mathrm{~m}$. In the middle portion of the main bridge, between piers P17 and P26, the elevation of the deck increases from $40.8 \mathrm{~m}$ at P17 and P26 to the highest elevation of 59.06 $\mathrm{m}$ at the central span P21-P22. This span is called the navigation span. The elevation of 59.06 $\mathrm{m}$ above MSL provides a $49 \mathrm{~m}$ vertical clearance for marine vessel traffic. The height of the piers of the navigation span is approximately $75 \mathrm{~m}$.

Both the approach bridges and the main bridge were built of precast concrete segments which were assembled using post-tensioned tendons. A detailed description of the bridge 
and the construction methods is given in [4]. Because this study is associated with typical spans of the main bridge, the discussion in the rest of this section will be focussed on structural features of the main bridge.

The structural system of the main bridge consists of a series of rigid portal frames connected by simply supported girders, which are called drop-in girders (Fig. 1). Every second span is constructed as a portal frame, and all other spans are constructed using drop-in girders. In total, there are 21 portal frames in the main bridge. This structural system was selected to prevent progressive collapse of the bridge due to extreme effects of wind, ice, seismic, and traffic loads, and ship collisions.

Figure 2 shows a typical portal frame of the main bridge. The girder consists of two 192.5 $\mathrm{m}$ double cantilevers and a $55 \mathrm{~m}$ long segment between them. The connections between this segment and the cantilevers are detailed to behave as rigid joints. The drop-in girders that connect the frames are also shown in Fig. 2, in the spans adjacent to the portal frame span. The length of the drop-in girders is $60 \mathrm{~m}$. Each of the drop-in girders sits on the overhangs of the two adjacent portal frames. Four specially designed elastomeric bearings are used as supports. One of the bearings is fixed against translations and the remaining three allow translations of the girder only in the longitudinal direction. All four bearings allow rotations about all axes. This configuration of the bearings provides a hinge connection at one end, and longitudinal sliding connection at the other end of the drop-in girder.

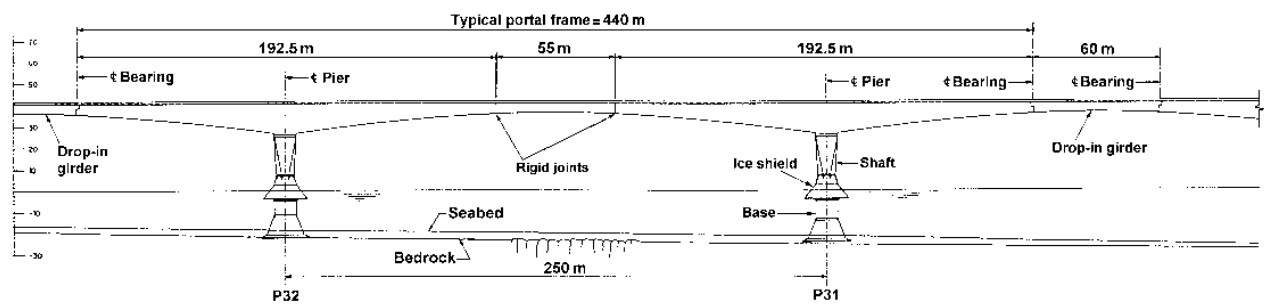

Figure 2. Typical portal frame.

The piers are constructed of two precast concrete units each, i.e., the pier base and the pier shaft (Fig. 2). The pier base is a hollow unit and has a circular cross section in plan with an outer diameter of $8 \mathrm{~m}$ at the top and $22 \mathrm{~m}$ at the footing. The pier shaft is also a hollow unit and consists of a shaft at the upper portion and an ice shield at the bottom portion of the pier. The cross section of the pier shaft varies from a rectangular section at the top to an octagonal section at the bottom of the shaft. Both the pier base and the pier shaft have very complex shapes. Detailed explanations for these and the geometrical properties of the piers can be found in [4]. 


\section{Seismic design parameters and seismic hazard for the bridge}

\subsection{Seismic design parameters}

The design life of 100 years and the safety index of 4.0 were the basic design requirements for the Confederation Bridge. These requirements were much higher than those prescribed in the highway bridge design codes available at the time when the bridge was designed. The specified design life and safety index for the Confederation Bridge required special studies in order to determine the seismic ground motion parameters at the bridge location.

The seismic ground motion parameters used in the design of the bridge were given in the design criteria specified by J. Muller International - Stanley Joint Venture Inc. [5]. These included the peak ground acceleration, the peak ground velocity, the peak ground displacement, and the seismic design spectrum for the bridge location. The methods for determining these parameters were described by [6]. Two methods were used for the estimation of the peak ground acceleration of the expected seismic motions at the bridge location. The first method was based entirely on probabilistic considerations. According to this method, the peak ground acceleration for the design service life of 100 years and the design safety index of 4.0 corresponded to an annual probability of exceedance of 0.00027 . The value of the peak ground acceleration for this probability of exceedance was found to be $\mathrm{A}=0.136 \mathrm{~g}$.

The second method was primarily based on engineering considerations. In this method, first, the peak ground acceleration was determined for a probability of exceedance of $10 \%$ during the design service life of 100 years. The background for this was to keep the same probability of exceedance during the service life as that required by the 1990 edition of the National Building Code of Canada (NBCC) [7]. Then, the acceleration value corresponding to $10 \%$ in 100 years probability of exceedance was increased by applying a factor of 1.43 representing the product of the commonly used importance factor of 1.3 , and an additional importance factor of 1.1 because of the unusual importance of the bridge. The resulting peak ground acceleration was $0.12 \mathrm{~g}$, and this value was adopted for the design. Using the same approach, the peak ground velocity was found to be $10.8 \mathrm{~cm} / \mathrm{s}$. Having the values for the peak ground acceleration (A) and the peak ground velocity $(\mathrm{V})$, a value for the peak ground displacement (D) of $5.9 \mathrm{~cm}$ was obtained using the relationship between $A, V$, and $D$, proposed by [8].

The 5\% damped elastic seismic design spectrum for horizontal seismic motions was developed using the foregoing values for the peak ground acceleration, velocity and displacement, and applying the corresponding spectral amplification factors proposed by [8] for the mean plus one standard deviation level. This level corresponds to a probability of $84 \%$ that the spectral amplification factors will not be exceeded. The parameters for the construction of the horizontal design spectrum are given in Table 1, adopted from the design criteria. It can be seen that the spectrum was defined assuming a constant spectral acceleration in the short period range $(T<0.5 \mathrm{~s})$, a constant spectral velocity in the intermediate period range $(0.5 \mathrm{~s}<\mathrm{T}<3.0 \mathrm{~s})$, and a constant spectral displacement in the long 
period range $(\mathrm{T}>3.0 \mathrm{~s})$, which is a common approach for constructing design spectra based on peak ground motions and spectral amplification factors [8]. The vertical design spectrum was taken as $2 / 3$ of the horizontal spectrum [5], which is also a common practice for defining vertical design spectra, based on the findings reported in [9].

\begin{tabular}{ccc}
\hline Period, $\mathrm{T}(\mathrm{s})$ & Governing parameter & Spectral acceleration $(\mathrm{g})$ \\
\hline$<0.5$ & Acceleration $=0.326 \mathrm{~g}$ & 0.326 \\
$0.5-3.0$ & Velocity $=24.8 \mathrm{~cm} / \mathrm{s}$ & $0.1589 / \mathrm{T}$ \\
$>3.0$ & Displacement $=11.8 \mathrm{~cm}$ & $0.48 / \mathrm{T}^{2}$ \\
\hline
\end{tabular}

Table 1. Parameters of the design spectrum for horizontal seismic motion; $5 \%$ damping [5].

Figure 3 shows the horizontal seismic design spectrum. The other spectrum in the figure, designated "uniform hazard spectrum" is discussed below.

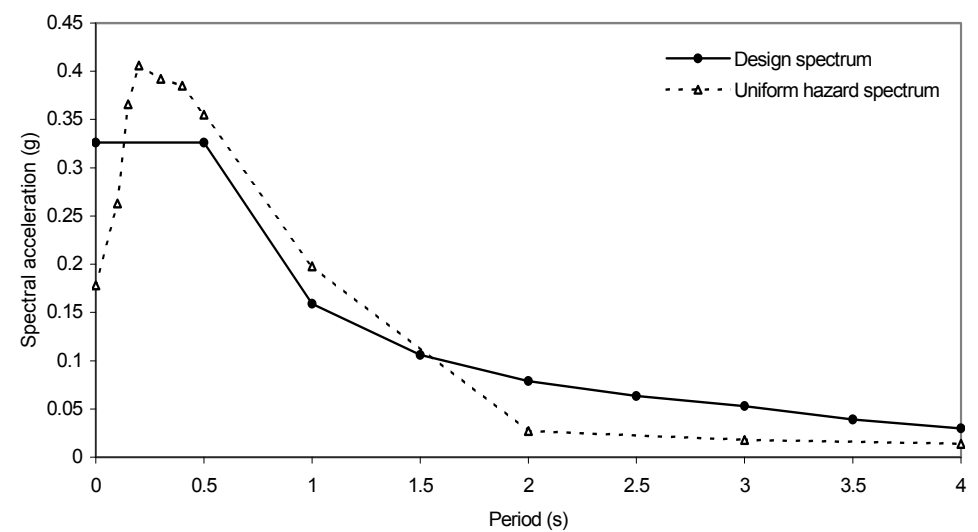

Figure 3. Design and uniform hazard spectra; $5 \%$ damping.

\subsection{Seismic hazard for the bridge location}

Since the development of the design parameters for the Confederation Bridge in early 1990s, there have been significant advances in the understanding of the seismic hazard in Canada. New source models, and most updated software have been used for the assessment of the seismic hazard. It should be mentioned, however, that there are still significant uncertainties in the estimation of seismic hazard. As pointed out by [10], the ground motion attenuation relations for eastern Canada are the major source of uncertainty in the seismic hazard estimations. This is because of lack of recordings of ground motions from strong earthquakes in eastern Canada for use in the calibration of the attenuation relations. It is noted that the ground motion attenuation relations for eastern Canada may change significantly as new events are recorded as reported in [10].

The seismic hazard in Canada is currently represented by uniform hazard spectra rather than by peak ground motions. A uniform hazard spectrum represents an acceleration 
spectrum with spectral ordinates that have the same probability of exceedance. Uniform hazard spectra can be computed for different probabilities and different confidence levels. Confidence levels of $50 \%$ (median) and $84 \%$ are typically used for uniform hazard spectra. These levels represent the confidence (in \%) that the spectral values will not be exceeded for the specified probability.

For the purpose of this study, Geological Survey of Canada (GSC) computed the uniform hazard spectrum for the bridge location for an annual probability of exceedance of 0.00027 and confidence levels of $50 \%$ and $84 \%$. Among the two confidence levels, the uniform hazard spectrum at the $84 \%$ confidence level was used in this study. The $84 \%$ (rather than $50 \%$ ) level was chosen since the spectral amplification factors used in the development of the design spectrum are for that level. The $84 \%$ level uniform hazard spectrum (UHS) is shown in Fig. 3. The spectral values for periods below $2.0 \mathrm{~s}$ were provided by GSC. For periods between $2.0 \mathrm{~s}$ and $4.0 \mathrm{~s}$, the spectrum was extended assuming a constant spectral velocity with the same value as that at $2.0 \mathrm{~s}$. This is the same as assumed in the defining of the spectral values in the intermediate period range of the design spectrum.

It can be seen in Fig. 3 that the uniform hazard spectrum is somewhat higher than the design spectrum for periods below $1.5 \mathrm{~s}$. As will be discussed later, this difference does not have significant effects on the seismic response of the bridge.

\subsection{Scenario earthquakes for the bridge location}

The seismic hazard at a given site represents the sum of the hazard contributions of different earthquakes at different distances from the site. For each site, however, there are a few earthquakes that have dominant contributions to the hazard. These earthquakes are normally referred to as scenario or predominant earthquakes. The shape of the uniform hazard spectrum for a given site, representing the seismic hazard for the site, depends on the magnitudes of the scenario earthquakes and the distances of these earthquakes from the site. In general, the dominant contribution to the short period ground motion hazard is from small to moderate earthquakes at small distances, whereas larger earthquakes at greater distance contribute most strongly to the long period ground motion hazard.

For the purpose of the selection of earthquake ground motions for use in the seismic analyses, it is necessary to determine the scenario earthquakes for the Confederation Bridge. This can be done by computing the seismic hazard contributions of selected magnitudedistance ranges that cover all possible magnitude-distance combinations. Figure 4, provided by Geological Survey of Canada, shows the magnitude-distance contributions for the Confederation Bridge for annual probability of exceedance of 0.000404 (i.e., $2 \%$ in 50 years). Such graph could not be produced for a probability of exceedance of 0.00027 because of the uncertainties in the hazard analysis due to the extrapolations relative to the current hazard models. However, it was reported by [11] that the predominant magnitude increases very slowly as probability decreases. Also, results reported in [12] indicated that the lowering of the probability has small effects on the predominant magnitude and distance values. Given this, the magnitude-distance contributions shown in Fig. 4 were considered to be representative of those for probability of exceedance of 0.00027 . 
(a)
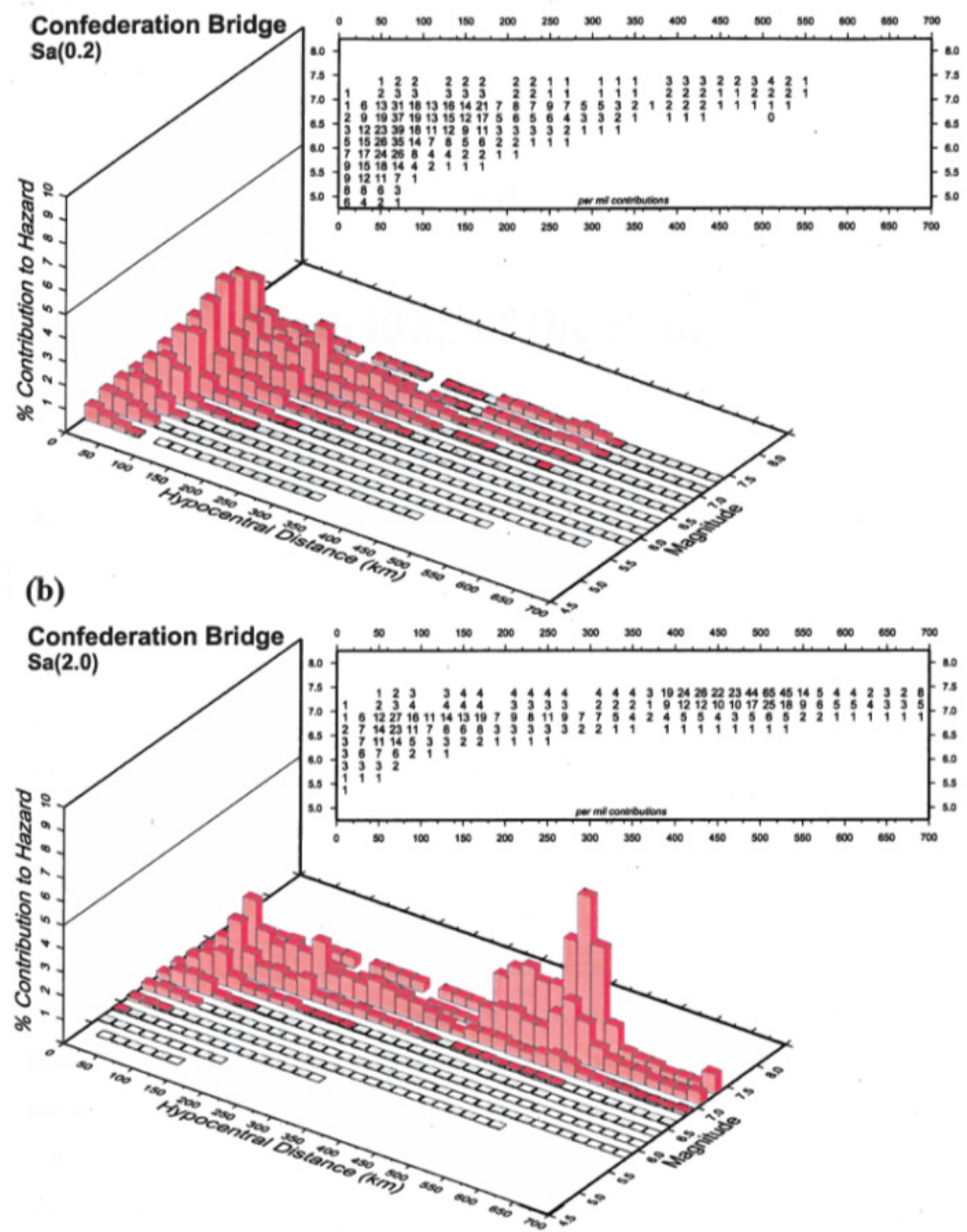

Figure 4. Magnitude-distance contributions to the seismic hazard of the Confederation Bridge, (a) for spectral acceleration at period of $0.2 \mathrm{~s}$, and (b)for spectral acceleration at period of $2.0 \mathrm{~s}$.

Figure 4(a) shows the contributions to the seismic hazard for period of $0.2 \mathrm{~s}$, representing the short period ground motion hazard, while Fig. 4(b) shows the contributions for period of $2.0 \mathrm{~s}$, representing the long period ground motion hazard. The contributions are computed for magnitude increments of 0.25 , and distance increments of $20 \mathrm{~km}$. It can be seen in Fig. 4(a) that the scenario earthquakes that have predominant contributions to the short period ground motion hazard are with magnitude ranging from 6 to 6.75 at distances of $60 \mathrm{~km}$ to 80 $\mathrm{km}$. Similarly, Fig. 4(b) shows that the scenario earthquakes that have predominant contributions to the long period ground motion hazard are with magnitudes ranging from 7.25 to 7.5 at distances of approximately $500 \mathrm{~km}$. 


\section{Modelling of the bridge}

The structural system of the bridge allows the development of a model of a selected segment of the bridge rather than modelling the entire bridge. Because of the repetitiveness of the units of the structural system (i.e., portal frames and drop-in girders) along the bridge, a proper model of a selected segment would be quite representative of the whole bridge.

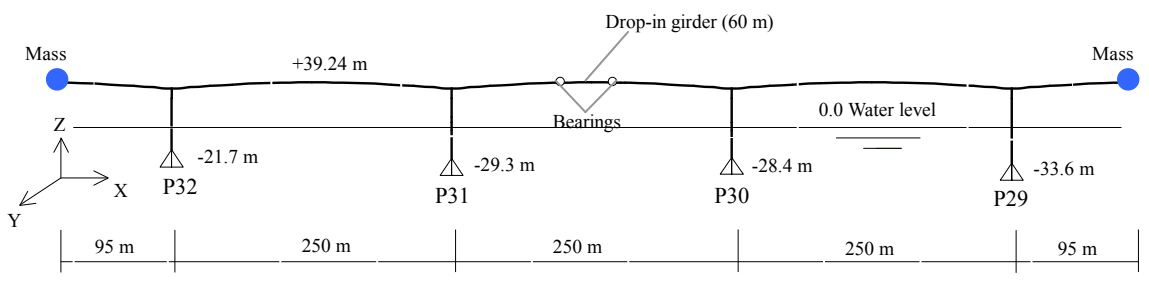

Figure 5. Model of two portal frames and one drop-in span using 3-D beam elements.

Figure 5 shows the model used in this study. It is a three-span frame model consisting of 3-D beam elements. The modelling was conducted using the computer program SAP 2000 [13]. The model represents the bridge segment between piers P29 and P32 (Fig. 1), which consists of two rigid portal frames (P29-P30 and P31-P32), and one drop-in span (P30-P31). This segment was modelled since it is the instrumented portion of the bridge, and recorded data is available for use in the calibration of the model. Also, the height of the piers of this segment is quite representative of the main bridge.

The model consists of 179 beam elements and 180 joints. The bridge girder is modelled by 123 elements, and each pier is modelled by 14 elements. The interaction with the adjacent drop-in girders (left of P32, and right of P29) was modelled by adding masses at the ends of the overhangs, as shown in Fig. 5. A half the mass of each drop-in girder was added at the end of the supporting overhang in transverse and vertical directions, full mass was added in the longitudinal direction for a hinge connection, and no mass was added in the longitudinal direction for a sliding connection. Similarly, vertical forces from a half the weight of each drop-in girder were applied at the ends of the overhangs.

In addition to the three-span model (Fig. 5), a single-span model consisting of a single portal frame (P31-P32), and a five-span model with three portal frames and two spans with drop-in girders (between P29 and P34; Fig. 1) were also considered. While the natural periods and mode shapes of these three models were quite comparable, the three-span model was chosen for the analysis in this study because it provides results for both the portal frame spans and the spans with drop-in girders, and requires an acceptable computation time for the analysis. The single-span model does not provide results for the drop-in girder, and the five-span model requires an excessive computation time. Note that the segment shown in Fig. 5 is normally used as a typical segment in studies on the behaviour of the Confederation Bridge [e.g., 14,15]. 


\section{Calibration of the model using data of full scale test}

The model shown in Fig. 5 was calibrated using records of vibrations and tilts of the bridge obtained during a full scale tests of the bridge were conducted on April 14, 1997, about two months before the official opening of the bridge. The objectives of the tests were: (i) to measure the deflection of the bridge pier under static loads, and (ii) to measure the free vibrations of the pier due to a sudden release of the static load. The instrumentation of the bridge (Fig. 6) was used to measure the bridge response during the pull tests. It consists of 76 accelerometers and 2 tiltmeters. The accelerometers were used to measure acceleration time histories of the response of the bridge. The two tiltmeters installed at locations 3 and 4 of pier P31 were used to measure the tilts of the pier.

a)

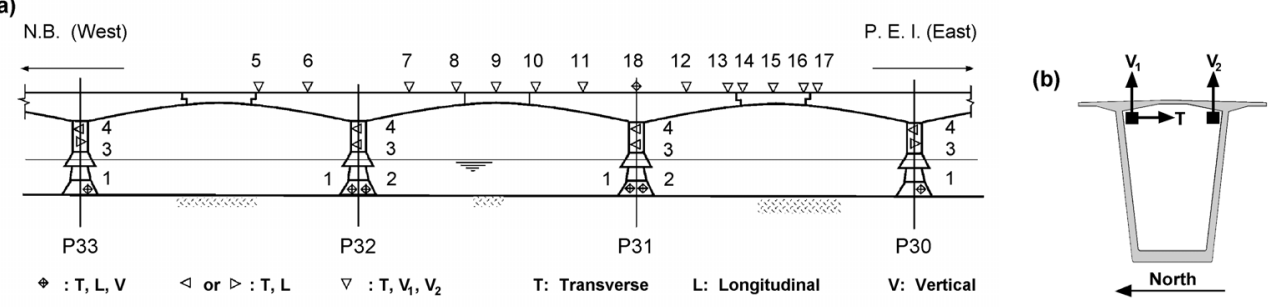

Figure 6. Locations of accelerometers: (a) instrumented sections of the bridge girder and piers, and (b) locations of accelerometers in the girder.

The first pull test was a static test. Using a steel cable, a powerful ship pulled pier P31 in the transverse direction of the bridge. The pulling was at the top of the ice shield, approximately $6 \mathrm{~m}$ above the mean sea level. The force was increased steadily up to $1.43 \mathrm{MN}$, and then released slowly.

The second pull test was a dynamic test. In this test, the load was applied at a slow rate up to $1.40 \mathrm{MN}$ and then suddenly released. This triggered free vibrations of the bridge, which were recorded by several accelerometers. The acceleration time history of the transverse vibrations recorded at the middle of span P31-P32 (location 9 in Fig. 6) along with the recorded tilts at locations 3 and 4 were used in the calibration of the model.

The parameter that was varied in the calibration process was the foundation stiffness. Rotational springs in the longitudinal and transverse directions were introduced in the model, at the bases of the piers, to represent the foundation stiffness. A trial value of the stiffness of the springs was initially selected, and a number of iterations of static and dynamic elastic analyses were performed in order to determine the stiffness that provides a close match between the computed and the measured tilts and free vibrations of the bridge. In each iteration, the tilts and the response were computed by using a load function closely representing the actual loading during the test. A modulus of elasticity of the concrete of $40,000 \mathrm{MPa}$ was used in the analyses. This value was based on experimental data for the bridge [14], and is representative of the modulus of elasticity at the time when the test was conducted. 

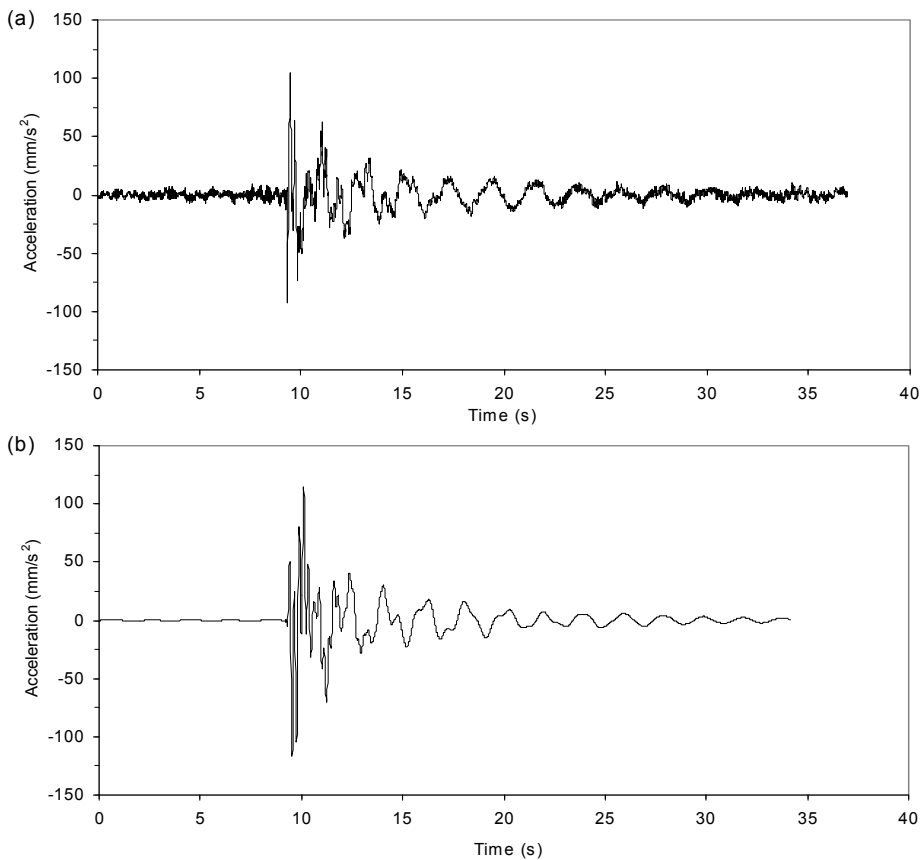

Figure 7. Acceleration time histories of transverse vibrations at midspan between piers P31 and P32 (a) measured, (b) computed.

It was found that the model with a rotational stiffness of $3.35 \times 10^{9} \mathrm{kN} \cdot \mathrm{m} / \mathrm{rad}$ provides the best matching of the computed and measured responses. Figure 7 shows the measured and the computed acceleration time histories of the transverse vibrations of the bridge girder at the mid-span between piers P31 and P32, and Fig. 8 shows the Fourier amplitude spectra of these time histories. It can be seen in Fig. 7 that the computed response of the bridge is very similar to the measured response. Also, Fig. 8 shows that the Fourier amplitude spectra of the computed and the measured responses are quite close. Note that the first two predominant frequencies of the computed response of $0.51 \mathrm{~Hz}$ and $1.28 \mathrm{~Hz}$ correspond respectively to the $7^{\text {th }}$ and the $18^{\text {th }}$ modes of the model.

Table 2 shows the natural periods of the first ten modes obtained from dynamic analysis of the model. For illustration, the vibrations of the first five modes are presented in Fig. 9. It is necessary to mention that a similar model was developed by Lau et al. [15] using the computer program COSMOS [16]. The natural periods and mode shapes of that model are very close to those of the model developed in this study.

It is useful to mention that certain variations of the dynamic properties of the model are expected due to different effects. For example, the modulus of elasticity increases with the age of concrete and varies due to temperature changes. Also, the responses used in the calibration of the model are substantially smaller than those from expected seismic motions at the bridge location. A comprehensive investigation of the possible variations of the 
dynamic properties due to the foregoing effects conducted by [17] showed that these variations are insignificant from practical point of view, therefore, the model developed as described above is considered appropriate for the seismic evaluation of the bridge.

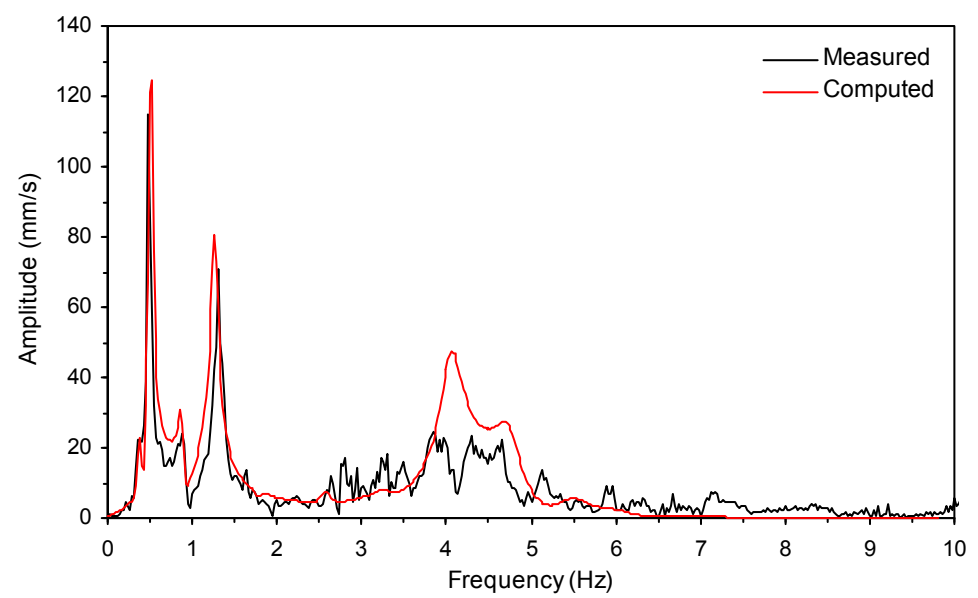

Figure 8. Fourier amplitude spectra of measured and computed acceleration time histories of vibrations at midspan between piers P31 and P32.

\begin{tabular}{ccl}
\hline Mode No. & Period $(\mathrm{s})$ & Mode type \\
\hline 1 & 3.13 & Transverse \\
2 & 2.99 & Transverse \\
3 & 2.72 & Transverse \\
4 & 2.48 & Transverse \\
5 & 2.22 & Transverse \\
6 & 2.13 & Longitudinal \\
7 & 2.08 & Transverse \\
8 & 2.01 & Longitudinal \\
9 & 1.54 & Vertical \\
10 & 1.43 & Vertical \\
\hline
\end{tabular}

Table 2. Natural periods of the first 10 modes of the bridge model.

\section{Seismic excitations for time-history analysis}

Given the uncertainties in the estimation of the seismic hazard for eastern Canada, a number of time-history analyses were conducted using excitation motions well beyond the scenario earthquake motions for the bridge location determined from the seismic hazard analysis as discussed in Section 3.3. In total, five groups of different seismic excitations were considered. 


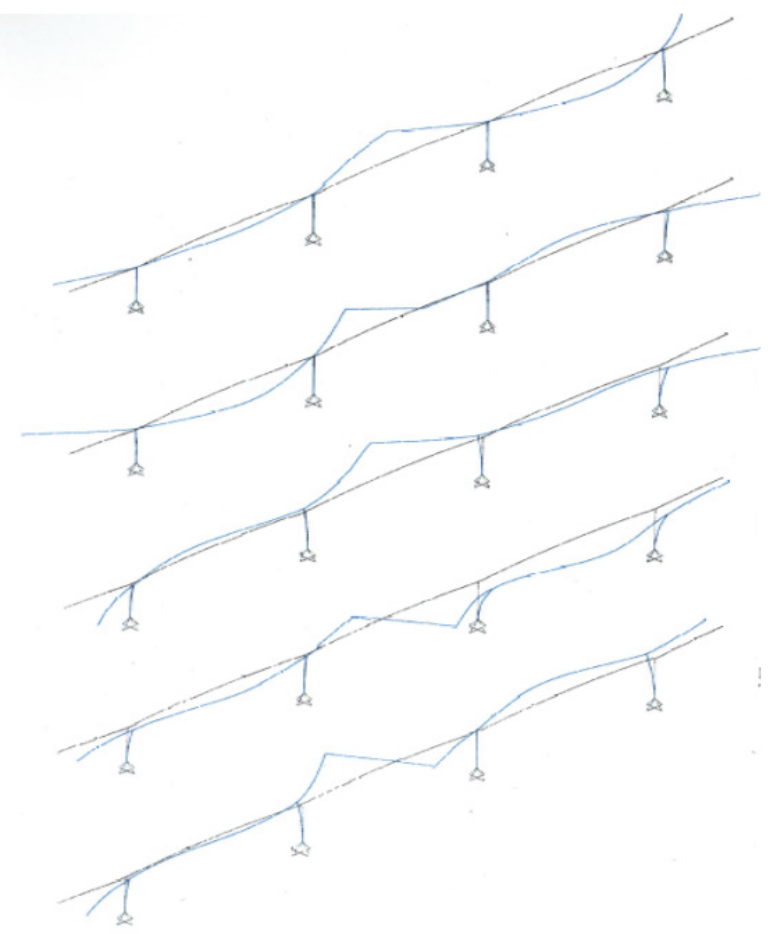

Figure 9. Mode shapes of the bridge model.

Because of lack of strong seismic motion records in eastern Canada, two ensembles of ground motion records obtained during strong earthquakes around the world were used in this study. The ensembles are described in $[18,19]$ and are characterized by different peak ground acceleration to peak ground velocity ratios (A/V ratios). The average $\mathrm{A} / \mathrm{V}$ ratio (A in $\mathrm{g}$, and $\mathrm{V}$ in $\mathrm{m} / \mathrm{s}$ ) of the records of one of the ensembles is 2.06, and that of the other ensemble is 0.48 . Based on the $\mathrm{A} / \mathrm{V}$ ratios of the records, the ensembles are referred to as the high and low $\mathrm{A} / \mathrm{V}$ ensembles. In general, high $\mathrm{A} / \mathrm{V}$ ratios are characteristics of seismic motions from small to moderate earthquakes at short distances, and low $\mathrm{A} / \mathrm{V}$ ratios are characteristics of seismic motions from large earthquakes at large distances. Regarding the frequency content, high $\mathrm{A} / \mathrm{V}$ motions normally have a high frequency content, and low $\mathrm{A} / \mathrm{V}$ motions have a low frequency content. Seismic motions with a high frequency content are characterized by predominant frequencies higher than approximately $2 \mathrm{~Hz}$ (i.e., periods lower than $0.5 \mathrm{~s}$ ), and seismic motions with a low frequency content are characterized by predominant frequencies lower than $2 \mathrm{~Hz}$ (i.e.,periods longer than $0.5 \mathrm{~s}$ ).

In addition to the foregoing ensembles, ground motion records obtained during the 1988 Saguenay, Quebec earthquake, and the 1982 Miramichi, New Brunswick earthquake were used as excitation motions. Also, stochastic seismic motions generated for eastern Canada were used. 


\subsection{High A/V excitations}

It is well known that seismic ground motions in eastern Canada are characterized by high frequency content and high $\mathrm{A} / \mathrm{V}$ ratios $[19,20]$. As discussed above, an ensemble of records with high $\mathrm{A} / \mathrm{V}$ ratios from strong earthquakes around the world [19] was adopted for the analysis. The ensemble consisted of 13 pairs of horizontal and vertical records. The magnitudes of the earthquakes are between 5.25 to 6.9 , the distances are between $4 \mathrm{~km}$ to 26 $\mathrm{km}$. The average $\mathrm{A} / \mathrm{V}$ ratio of the records is 2.06 . It is necessary to mention that the magnitudes of these earthquakes cover the magnitude range of 6.0 to 6.75 of the scenario earthquakes for the short period ground motion hazard for the bridge location as discussed in Section 3.3.

The excitation motions for the time-history analysis were obtained by scaling the records to the peak ground velocity of $7.1 \mathrm{~cm} / \mathrm{s}$ computed by GSC for an annual probability of exceedance of 0.00027 . These excitations are referred to as high $\mathrm{A} / \mathrm{V}$ excitations. Figure 10 shows the acceleration response spectra of the scaled horizontal records of the ensemble. For comparison, the design spectrum is superimposed on the figure. It can be seen that the spectra of the records exceed significantly the design spectrum for periods shorter than approximately $0.5 \mathrm{~s}$, and the spectra are well below the design spectrum for periods longer than $0.5 \mathrm{~s}$.

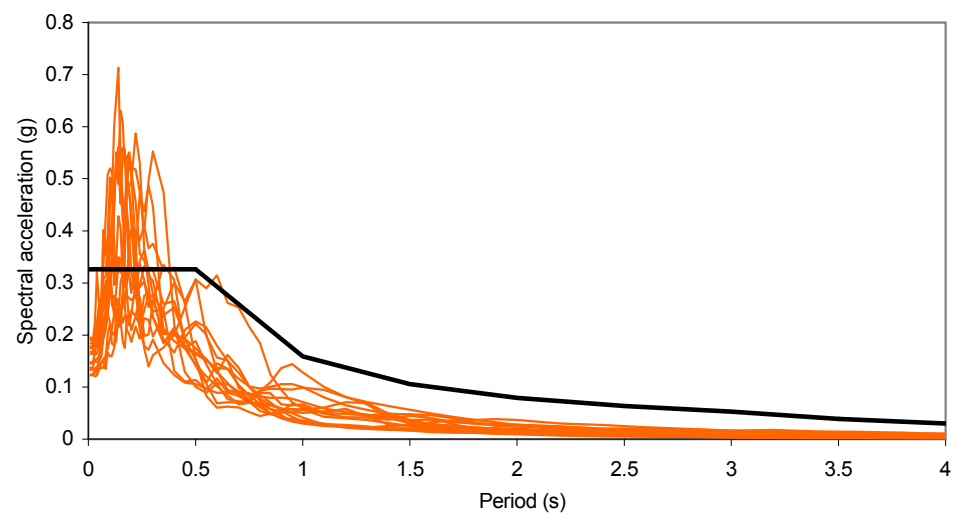

Figure 10. Design spectrum and scaled response spectra of high $\mathrm{A} / \mathrm{V}$ excitations; $5 \%$ damping.

\subsection{Low $\mathrm{A} / \mathrm{V}$ excitations}

The low A/V ensemble consisted of 15 pairs of horizontal and vertical records of seismic ground motions [18]. The records were taken during strong earthquakes around the world with magnitudes ranging from 6.3 to 8.1. The distances at which the records were taken were within the range from $38 \mathrm{~km}$ to $469 \mathrm{~km}$. The average A/V ratio of the records is 0.48 . Both the magnitudes and the distances cover the magnitude and distance ranges of the scenario earthquakes for short and long period ground motion hazards for the bridge location determined from the seismic hazard analysis (see Section 3.3). 


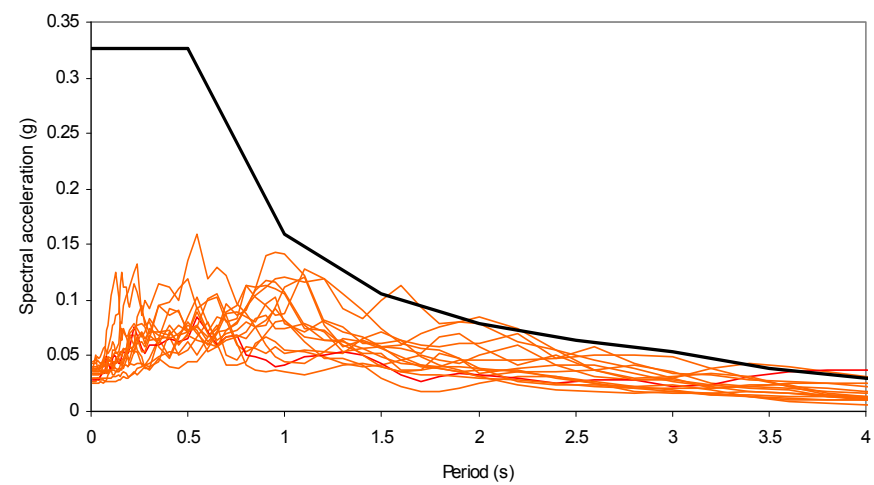

Figure 11. Design spectrum and scaled response spectra of low $\mathrm{A} / \mathrm{V}$ excitations; $5 \%$ damping.

Figure 11 shows the acceleration response spectra of the horizontal records of the low A/V ensemble scaled to the peak ground velocity of $7.1 \mathrm{~cm} / \mathrm{s}$. The design spectrum is also included in the figure. It can be seen that the spectra for the low $\mathrm{A} / \mathrm{V}$ records are all enveloped by the design spectrum. Given this, no time-history analyses were conducted for this ensemble.

\subsection{Saguenay earthquake excitations}

It was of special importance for this study to investigate the performance of the bridge when subjected to seismic motions from earthquakes in eastern Canada. On November 25, 1988, an earthquake of magnitude of 5.7 occurred in the Saguenay region of the province of Quebec. This was the most significant earthquake in the past 50 years in eastern North America. Ground motion records were obtained at 16 sites at distances ranging from $43 \mathrm{~km}$ to $525 \mathrm{~km}[21,22]$. The response spectra for all horizontal records were scaled to the peak ground velocity for the bridge location of $7.1 \mathrm{~cm} / \mathrm{s}$ and were compared with the design spectrum. Based on the comparison, 5 horizontal records and the companion vertical records were selected for the analysis. The scaled spectra of the horizontal records together with the design spectrum are shown in Fig. 12.

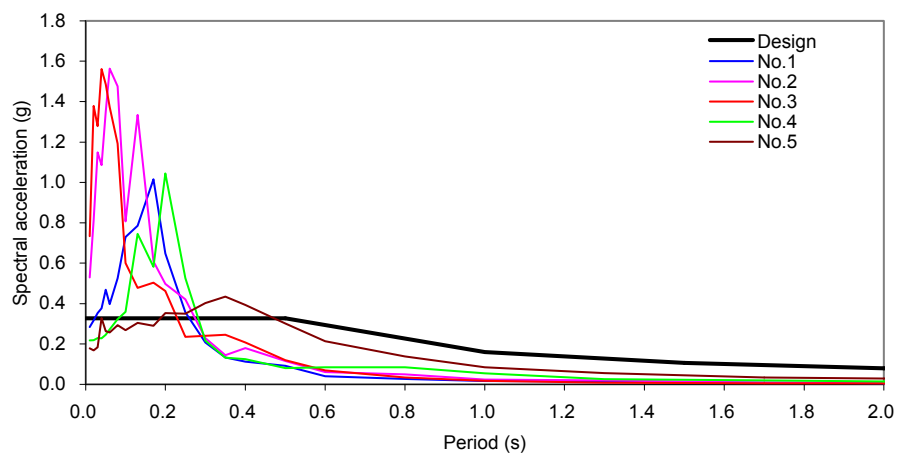

Figure 12. Design spectrum and scaled response spectra of Saguenay earthquake excitations; $5 \%$ damping. 
It can be seen in the figure that the scaled spectra of the Saguenay earthquake motions are significantly higher than the design spectrum for periods below $0.25 \mathrm{~s}$. The highest spectra (i.e., spectra of records No. 2 and No. 3) exceed the design spectrum by a factor of approximately 5 .

\subsection{Miramichi earthquake excitations}

In 1982, several earthquakes occurred in the Miramichi region of the province of New Brunswick [23]. The epicentres of earthquakes were approximately $150 \mathrm{~km}$ from the bridge site. By considering the response spectra, three records representing the strongest motions during the earthquakes were selected for this study. It was found that the $\mathrm{A} / \mathrm{V}$ ratios of the records are very high (about 11). Consequently, the ground motions from the Miramichi earthquakes are dominated by very short period (i.e., very high frequency) motions. The selected records were scaled to the peak ground velocity of $7.1 \mathrm{~cm} / \mathrm{s}$ for the bridge location, and the scaled response spectra of the horizontal records are shown in Fig. 13. It can be seen clearly in Fig. 13 that the ground motions of the Miramich earthquakes are dominated by very short period (i.e., about $0.04 \mathrm{~s}$ ). Figure 13 also shows that for the period of $0.04 \mathrm{~s}$, the spectral acceleration for the strongest motion (i.e., record. No. 1) is approximately 9 times larger than the value of the design spectrum.

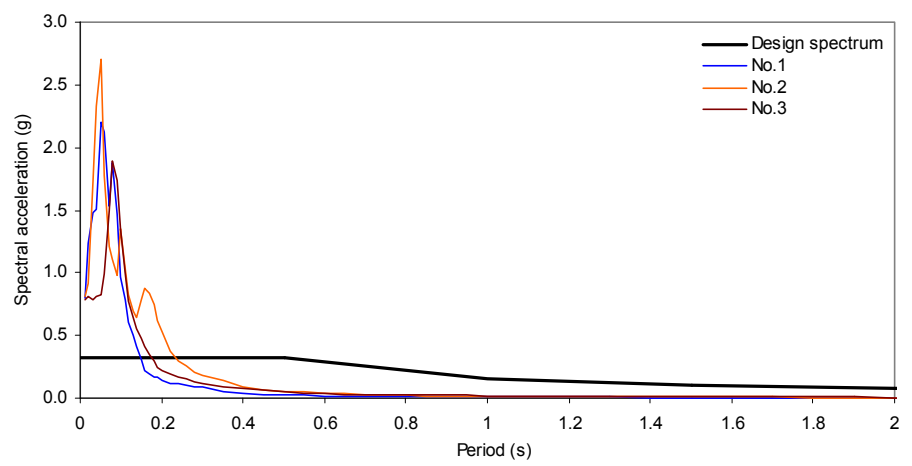

Figure 13. Design spectrum and scaled response spectra of Miramichi earthquake excitations; $5 \%$ damping.

\subsection{Simulated excitations}

In addition to the "real" records of seismic ground motions discussed above, "simulated" acceleration time histories (i.e., accelerograms) were also used as excitation motions. As reported by [11] seismic hazard for eastern Canadian sites can be approximated using a magnitude $M=6.0$ event to represent the short-period hazard, and $M=7.0$ event to represent the long-period hazard. They simulated ground motion accelerograms for eastern Canada for $\mathrm{M}=6.0$ and $\mathrm{M}=7.0$, and for different distances. For each distance, four accelerograms were simulated for a probability of exceedance of $2 \%$ in 50 years (i.e., annual probability of exceedance of 0.0004 ). 
Since the seismic hazard based on the service life and the importance of the bridge corresponds to an annual probability of exceedance of 0.00027 , it was necessary to scale the simulated accelerograms to be consistent with the uniform hazard spectrum (UHS) for a probability of exceedance of 0.00027 (Fig. 3). To determine the short-period hazard motions for the bridge, the simulated accelerograms for the $M=6.0$ event were scaled to have the same spectral values at the period of $0.2 \mathrm{~s}$ as that of the UHS for the bridge location. Similarly, the long-period hazard motions were obtained by scaling the simulated accelerograms for the $\mathrm{M}=7.0$ event to have the same spectral values as that of the UHS at the period of $2.0 \mathrm{~s}$.

(a)
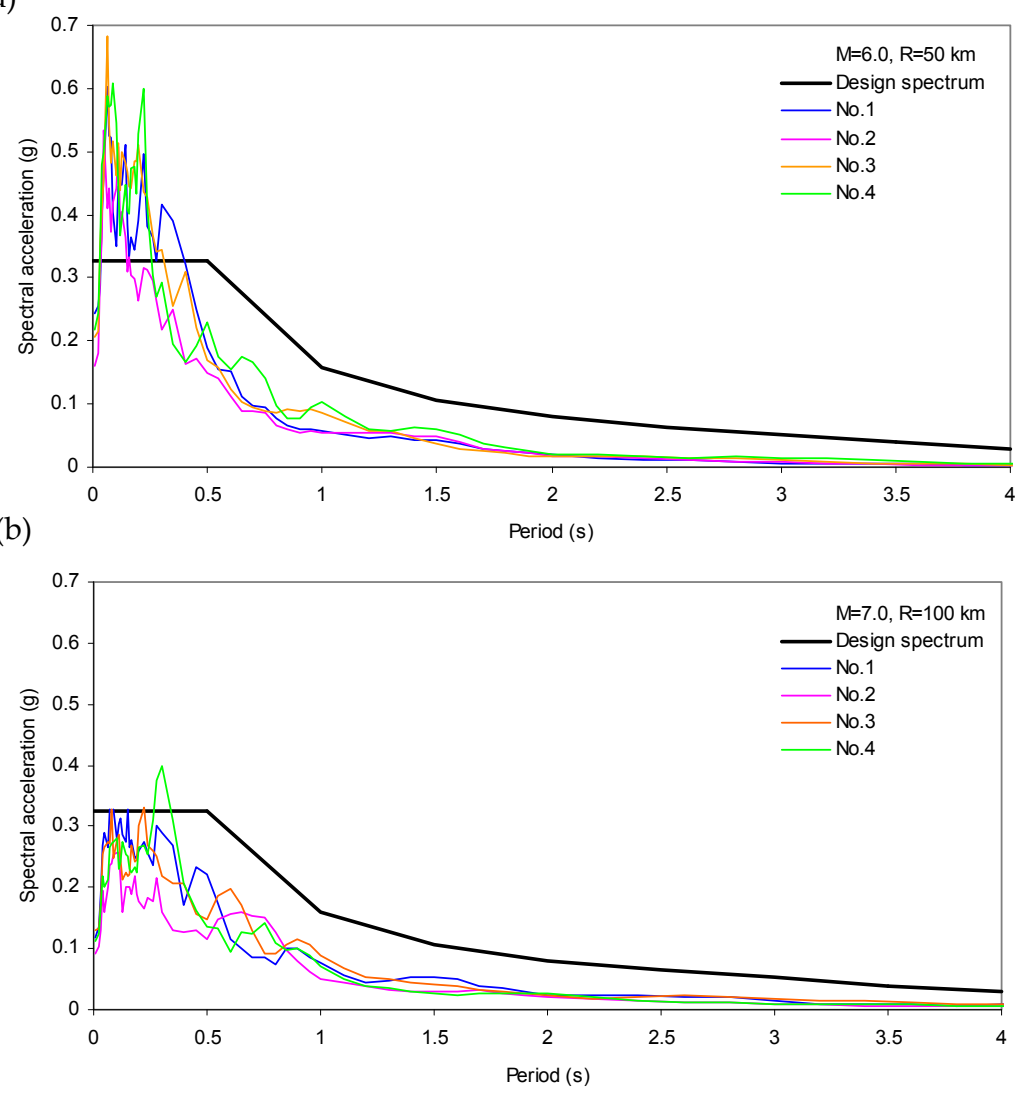

Figure 14. Design spectrum and scaled response spectra of simulated excitations; $5 \%$ damping (a) short-period hazard motions, (b) long-period hazard motions.

Trial time-history analyses showed that the largest responses of the bridge model are associated with the scaled accelerograms corresponding to the epicentral distances of $R=50 \mathrm{~km}$ for the $M=6.0$ event and $R=100 \mathrm{~km}$ for the $M=7.0$ event, and therefore, only these accelerograms were considered. The response spectra of the scaled short-period hazard accelerograms $(\mathrm{R}=50$ $\mathrm{km}, \mathrm{M}=6.0)$ and long-period hazard accelerograms ( $\mathrm{R}=100 \mathrm{~km}, \mathrm{M}=7.0)$ are shown in Figs. 14(a) 
and 14(b) respectively. It can be seen in Fig. 14(a) that the spectra of the short-period hazard accelerograms exceed the design spectrum by a factor of approximately 2.5 for periods below $0.2 \mathrm{~s}$. On the other hand, the spectra of the long-period hazard accelerograms (Fig. 14(b)) are only about $20 \%$ higher than the design spectrum for periods below 0.3 s. Given these observations, only the short-period hazard accelerograms were used as excitation motions in the time-history analysis.

\section{Dynamic analysis and results}

For the purpose of the seismic evaluation of the bridge, dynamic analyses were conducted on the bridge model to determine the responses due to seismic actions represented by the uniform hazard spectrum and the selected sets of records. Elastic material properties of the model were assumed in the analyses. The dynamic analyses included both responsespectrum analyses and time-history analyses.

\section{Response-spectrum analyses}

Response-spectrum analyses were performed for seismic actions represented by the uniform hazard spectrum. Separate response-spectrum analyses were carried out for the following two cases of seismic actions: (i) seismic actions in the longitudinal and vertical directions of the model; and (ii) seismic actions in the transverse and vertical directions. These two cases were considered appropriate since the longitudinal and the transverse modes are well separated, and the vertical modes are combined mainly with the longitudinal modes. The horizontal and the vertical actions were applied simultaneously at the bases of the piers. The horizontal seismic actions were represented by the horizontal uniform hazard spectrum (UHS) (Fig. 3), and the vertical actions were represented by a spectrum obtained by multiplying the horizontal UHS by $2 / 3$. The factor of $2 / 3$ is commonly used for defining vertical design spectra relative to horizontal spectra [9].

The analyses included the first 100 modes, which covered all natural periods above $0.02 \mathrm{~s}$. A modal damping of $5 \%$ was used for all the modes. The response maxima at each joint of the models were computed by combining the modal responses using the complete quadratic combination (CQC) rule.

As required by the Canadian Highway Bridge Design Codes [24], the mass participation of the modes considered in the analysis is larger than $90 \%$ in each of the three principal directions of the model. Namely, the amounts of the mass participation of the longitudinal, transverse and vertical modes used in the analysis are $95.3 \%, 95.5 \%$ and $93.6 \%$ respectively.

\section{Time-history analyses}

Time-history analyses were conducted to determine the responses of the model subjected to the records of the selected sets. As in the response-spectrum analysis, simultaneous seismic excitations in the longitudinal and vertical directions, and in the transverse and vertical directions of the model were used in the time-history analysis. In each analysis, the seismic excitations consisted of a pair of scaled horizontal and vertical acceleration time histories applied at the bases of the piers. 
The mode-superposition method was used in the time-history analysis. As in the responsespectrum analysis, the first 100 modes and modal damping of $5 \%$ for all the modes were considered in the time-history analysis. The response time histories were obtained at equal time interval of $0.005 \mathrm{~s}$.

\section{Discussion of results}

The response quantities obtained from both the response-spectrum analysis and the timehistory analysis included bending moments, shear forces, axial forces, and displacements. A detailed review of the response results showed that the observations from the shear forces and the axial forces were the same as those from the bending moments. Given this, only the bending moments and the displacements were used for the evaluation of the seismic performance of the bridge. However only the results for bending moments are shown there, the results for deflections can be found in [17].

For simplicity in discussing the results, the simultaneous excitations in the longitudinal and vertical directions are referred to as excitations in the longitudinal direction (or longitudinal excitations), and those in the transverse and vertical directions are referred to as excitations in the transverse direction (or transverse excitations). This is the case for both the responsespectrum and the time-history analyses.

To assist in understanding the results from the analyses, it is useful to describe the convention for the moments, as used in this study. In reference to the coordinate system shown in Fig. 5, longitudinal moments in the bridge girder are those that act about the Yaxis, and transverse moments are those that act about the Z-axis. For the piers, the moments that result from longitudinal excitations and act about the $Y$-axis are referred to as "moments in the longitudinal direction", and those that result from transverse excitations and act about the $\mathrm{X}$-axis are referred to as "moments in the transverse direction".

The moments at the joints of the model resulting from the response-spectrum analysis represent the maximum absolute values and by definition are positive. The time-history analysis provided a comprehensive set of results for each excitation motion. Time histories and maximum positive and negative values for the moments and displacements were obtained for the joints of the model. Moment and displacement envelopes for both the girder and the piers were determined using the largest absolute values of the computed (positive and negative) maxima for each of the selected sets of ground motions.

The comparisons of bending moments are shown in Figs. 15 and 16. Figure 15(a) shows the envelopes of the longitudinal moments in the bridge girder for seismic actions in the longitudinal direction, and Fig. 15(b) shows the envelopes of the transverse moments for seismic actions in the transverse direction. The moment envelopes are plotted using the corresponding values at selected sections along the bridge girder. Similarly, Figs. 16(a) and 16(b) present the moment envelopes for pier P31 for excitations in the longitudinal and transverse directions respectively. The moment envelopes for the other piers are similar to those for pier P31, and they are not shown here. The designation "Design" in Figs. 15 and 16 
is for the design responses which were calculated by [7], and "UHS" is for the responses due to seismic actions represented by the uniform hazard spectrum. Furthermore, the designations "World-wide", "Saguenay", "Miramichi", and "Simulated" are respectively for the responses due to the selected world-wide records - short-period set (Fig. 10), the Saguenay records (Fig. 12), the Miramichi records (Fig. 13), and the simulated motions short-period hazard set (Fig. 14(a)).

For the purpose of clarity, the results from the response-spectrum analysis (i.e., the "Design" and the "UHS" results) are discussed first. It can be seen from Fig. 15(a) that for the seismic actions in the longitudinal direction, the UHS envelope of the moments in the bridge girder is somewhat higher than the design envelope. Also, the values of the UHS envelope for the pier (Fig. 16(a)) resulting from the longitudinal seismic actions are larger than those of the design envelope in the upper $25 \mathrm{~m}$ of the pier. The largest differences are approximately $20 \%$. These observations for the longitudinal seismic actions were expected because the periods of the predominant longitudinal and vertical modes of the bridge are shorter than $1.5 \mathrm{~s}$, i.e., these are within the range in which the uniform hazard spectrum is higher than the design spectrum (Fig. 3). For seismic actions in the transverse direction, the UHS envelopes of the moments in the bridge girder and in the pier (Figs. 15(b) and 16(b), respectively) are all smaller than the design values. This is because the uniform hazard spectrum is lower than the design spectrum for the periods of the predominant transverse modes, i.e., periods longer than approximately $2.0 \mathrm{~s} \mathrm{(Fig.} \mathrm{3).}$

The $20 \%$ exceedance of the design responses by those from the UHS seismic actions in the longitudinal direction does not represent any concern regarding the seismic safety of the bridge. This is because of the following two reasons. First, conservative assumptions are involved in the design through the use of factored material strengths and specified safety factors, and therefore the actual capacity (i.e., resistance) of the bridge is substantially larger than the demands due to design loads. For example, considering only the resistance factors for concrete and reinforcing steel used in the design (i.e., $\phi_{\mathrm{c}}=0.75$ and $\phi_{\mathrm{s}}=0.85$, as specified in the Design Criteria [5]), the nominal flexural resistance of the bridge is about $20 \%$ larger than the design resistance. Other safety factors involved in the design, associated with the specified safety index [5], provide even larger resistances relative to the design resistance of the bridge.

The second reason is related to the conservatism of the response resulting from the uniform hazard spectrum. By definition, the uniform hazard spectrum at the bridge location represents the envelope of the spectral contributions of all possible earthquakes in the surrounding area that affect the seismic hazard at the location. This implies that the seismic response resulting from the uniform hazard spectrum represents the envelope of the response contributions from earthquakes with different magnitudes and at different distances from the bridge location, assuming that all the earthquakes occur at the same time. Obviously, the response from such combined earthquake actions is much larger than the responses from each of the earthquakes considered separately. These considerations clearly show that the response-spectrum analysis using the uniform hazard spectrum provides significantly larger responses than those from expected seismic ground motions represented by that spectrum. 

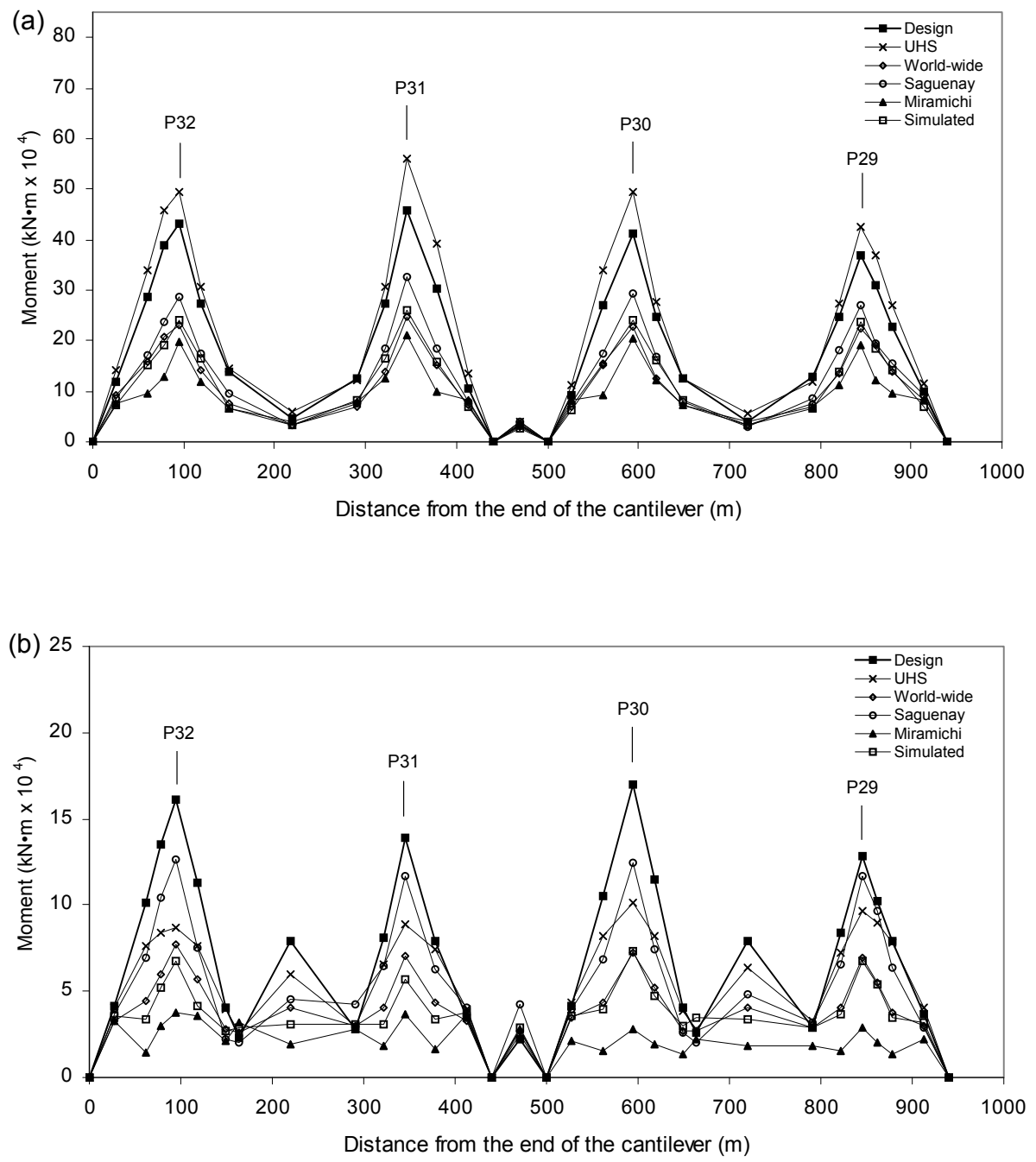

Figure 15. Moment envelopes for the bridge girder: (a) longitudinal moments, (b) transverse moments. Note: Piers P29 to P32 are indicated in the figures to identify the sections of the girder at the piers. 

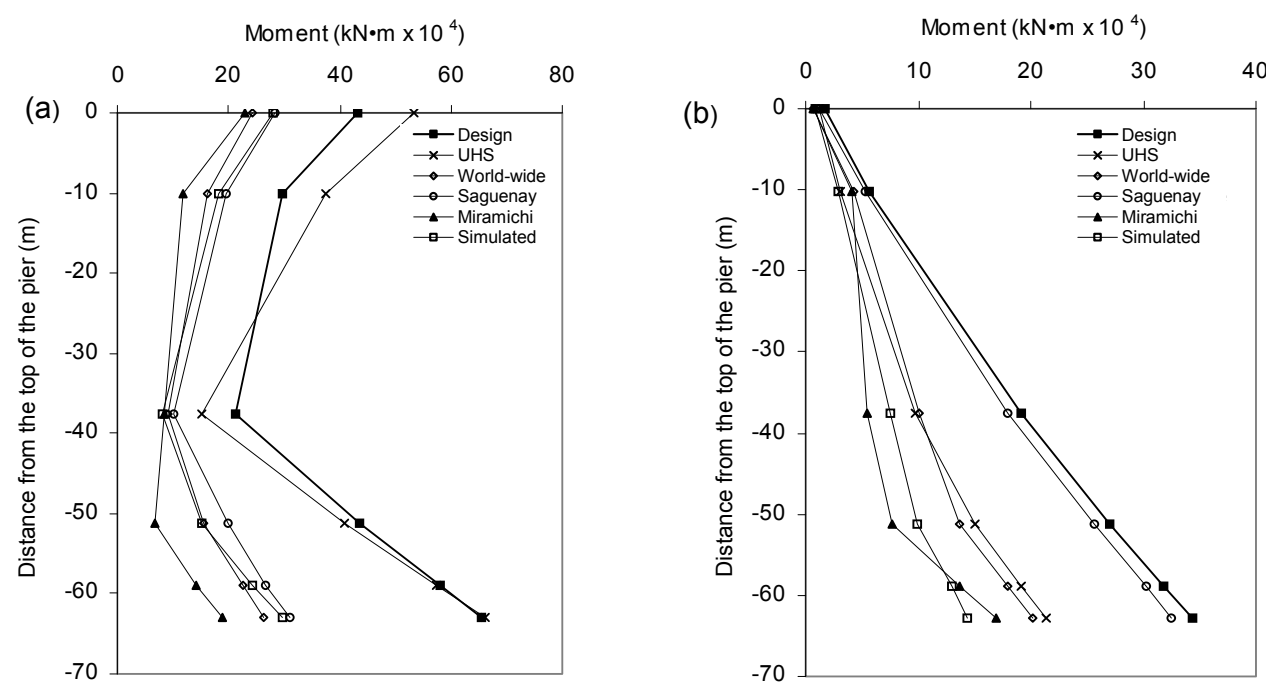

Figure 16. Moment envelopes for pier P31:(a) in longitudinal direction, (b) in transverse direction.

In regard to the response results obtained from the time-history analysis of the model subjected to the selected sets of excitations, it can be seen in Figs. 15 and 16 that the maximum moments are all smaller than the design responses for both the longitudinal and transverse excitations. This was expected based on the spectral characteristics of the excitation motions. As described earlier, the response spectra of the excitation motions used in the analysis (i.e., the World-wide short-period set, the Saguenay set, the Miramichi set, and the simulated short-period set) are all lower than the design spectrum for periods longer than approximately $0.5 \mathrm{~s}$ (Figs. 10, 12-14), i.e., within the period range of the longitudinal and transverse modes that produce almost the entire response. The contributions of the modes with periods below $0.5 \mathrm{~s}$, where the spectra of the excitation motions exceed the design spectrum, are very small.

\section{Conclusions}

The objective of this study was to investigate the performance of the Confederation Bridge due to seismic excitations expected at the bridge location. A finite element model of a typical segment of the bridge was subjected to selected seismic motions representative of the seismic hazard for the bridge location. The response results obtained from the dynamic analysis of the model were compared with the seismic design parameters. The following are the main conclusions from this study:

- The responses from the linear time-history analyses (displacements and forces) were found to be smaller than those used in the design of the bridge.

- The longitudinal responses of some sections of the bridge obtained from the response spectrum analysis (i.e., for seismic actions represented by the horizontal and vertical 
uniform hazard spectra) were found to be about $20 \%$ larger than the design values. Considering the conservatism in the design through the use of factored material strengths and specified safety factors, as well as the characteristics of the uniform hazard spectra, the exceedance of the design responses by $20 \%$ does not represent any concern regarding the safety of the bridge.

- The general conclusion is that the seismic effects considered in the design are appropriate for the required safety during the service life of the bridge.

- A finite element model consisting of 3D beam elements is suitable for the Confederation Bridge provided that the foundation flexibility is taken into account in the modeling.

- The modeling method used in this study is considered to be applicable to single-box girder bridges in general.

\section{Author details}

Lan Lin

Department of Building, Civil and Environmental Engineering, Concordia University, Montreal, Canada

Nove Naumoski and Murat Saatcioglu

Department of Civil Engineering, University of Ottawa, Ottawa, Canada

\section{References}

[1] CSA. 1988. Design of highway bridges. Standard CAN/CSA-S6-88, Canadian Standards Association, Rexdale, Ontario.

[2] MTO. 1991. Ontario Highway Bridge Design Code. Ministry of Transportation of Ontario, Downsview, Ontario.

[3] MacGregor, J.G., Kenedy, D.J.L., Barlett, F.M., Chernenko, D., Maes, M.A., and Dunascegi, L. 1997. Design criteria and load and resistance factors for the Confederation Bridge. Canadian Journal of Civil Engineering, 24: 882-897.

[4] Tadros, G. 1997. The Confederation Bridge: an overview. Canadian Journal of Civil Engineering, 24: 850-866.

[5] JMS. 1996. Design criteria - Northumberland Strait Crossing Project. Revision 7.2. J. Muller International - Stanley Joint Venture Inc., San Diego, California.

[6] Jaeger, L.G., Mufti, A.A., Tadros, G., and Wong, P. 1997. Seismic design for the Confederation Bridge. Canadian Journal of Civil Engineering, 24: 922-933.

[7] NRC. 1990. National Building Code of Canada 1990. Institute for Research in Construction, National Research Council of Canada, Ottawa, Ontario.

[8] Newmark, N.M., and Hall, W.J. 1982. Earthquake spectra and design. Monograph, Earthquake Engineering Research Institute, Berkeley, California.

[9] Newmark, N.M., Blume, J.A., and Kapur, K.K. 1973. Seismic design spectra for nuclear power plants. Journal of the Power Division, Vol. 99, No. PO2, pp. 287-303. 
[10] Adams, J., and Atkinson, G. 2003. Development of seismic hazard maps for the proposed 2005 edition of the National Building Code of Canada. Canadian Journal of Civil Engineering, 30: 255-271.

[11] Tremblay, R., and Atkinson, G.M. 2001. Comparative study of the inelastic seismic demand of eastern and western Canadian sites. Earthquake Spectra, Vol. 17, No. 2, pp. 333-358.

[12] Halchuk, S., and Adams, J. 2004. Deaggregation of seismic hazard for selected Canadian cities. Proceedings of the 13th World Conference on Earthquake Engineering, Vancouver, B.C., Canada, Paper No. 2470.

[13] CSI. 2000. SAP 2000 integrated software for structural analysis and design, Version 7. Computers and Structures Inc., Berkeley, California.

[14] Ghali, A., Elbadry, M., and Megally, S. 2000. Two-year deflections of the Confederation Bridge. Canadian Journal of Civil Engineering, 27: 1139-1149.

[15] Lau, D.T., Brown, T., Cheung, M.S., and Li, W.C. 2004. Dynamic modelling and behaviour of the Confederation Bridge. Canadian Journal of Civil Engineering, 31: 379390.

[16] SRAC. 1994. COSMOS - Finite element analysis software. Structural Research and Analysis Corporation, Santa Monica, California.

[17] Lin, L. 2005. Seismic evaluation of the Confederation Bridge. M.A.Sc. thesis, Department of Civil Engineering, University of Ottawa, Ottawa, Ontario.

[18] Naumoski, N., Heidebrecht, A.C., and Rutenberg, A.V. 1993. Representative ensembles of strong motion earthquake records. EERG Report 93-1, Earthquake Engineering Research Group, McMaster University, Hamilton, Ontario.

[19] Naumoski, N., Tso, W.K., and Heidebrecht, A.C. 1988. A selection of representative strong motion earthquake records having different $\mathrm{A} / \mathrm{V}$ ratios. EERG Report 88-01, Earthquake Engineering Research Group, McMaster University, Hamilton, Ontario.

[20] Adams, J., and Halchuk, S. 2003. Fourth generation seismic hazard maps of Canada: Values for over 650 Canadian localities intended for the 2005 National Building Code of Canada. Open File 4459, Geological Survey of Canada, Ottawa, Ontario.

[21] Munro, P.S., and Weichert, D. 1989. The Saguenay earthquake of November 25, 1988 Processed strong motion records. Open File Report No. 1966, Geological Survey of Canada, Energy, Mines and Resources, Ottawa, Ontario.

[22] Friberg, P., Rusby, R., Dentrichia, D., Johnson, D., Jacob, K., and Simpson, D. 1988. The $M=6$ Chicoutimi earthquake of November 25, 1988, in the province of Quebec, Canada. Preliminary NCEER strong motion data report, Lamont-Doherty Geological Observatory of Columbia University, Palisades, N.Y.

[23] Weichert, D.H., Pomeroy, P.W., Munro, P.S., and Mork, P.N. 1982. Strong motion records from Miramichi, New Brunswick, 1982 aftershocks. Open File Report 82-31, Energy, Mines and Resources Canada, Ottawa, Ontario. 
[24] CSA. 2006. Canadian Highway Bridge Design Code. Standard CAN/CSA-S6-06, Canadian Standard Association (CSA), Mississauga, Ontario. 